DOI: $10.17516 / 1998-2836-0178$

УДК 547.993:543.421/424:543.429

\title{
Numerical Optimization of the Abies Ethanol Lignin \\ Sulfation Process with Sulfamic Acid \\ in 1,4-Dioxane Medium in the Presence of Urea
}

\author{
Aleksandr S. Kazachenko a, Natalya Yu. Vasilyeva ${ }^{a, b}$, \\ Irina G. Sudakova ${ }^{a}$, Vladimir A. Levdansky ${ }^{a}$, \\ Maxim A. Lutoshkin a and Boris N. Kuznetsov*a,b \\ ${ }^{a}$ Institute of Chemistry and Chemical Technology SB RAS \\ FRC "Krasnoyarsk Scientific Center SB RAS" \\ Krasnoyarsk, Russian Federation \\ ${ }^{b}$ Siberian Federal University \\ Krasnoyarsk, Russia Federation
}

Received 26.12.2019, received in revised form 10.02.2020, accepted 14.04.2020

\begin{abstract}
The process of abies ethanol lignin sulfation with sulfamic acid in 1,4-dioxane medium in the presence of urea was optimized by calculation methods. The influence of such factors, as the ratio of lignin/sulfating complex (L/SC), temperature and time of the sulfation process on the sulfur content in the resulting sulfated ethanol lignin and its yield, has been established. The variance analysis of the obtained mathematical models testifies their good predictive properties. The optimal conditions of abies ethanol lignin sulfation process, which provide the formation of water-soluble sulfated lignin with a high yield (to $100 \% \mathrm{wt}$.) and sulfur content (up to $7.9 \% \mathrm{wt}$.), have been established. They are: temperature of $95-100{ }^{\circ} \mathrm{C}$, the ratio $\mathrm{L} / \mathrm{SC} 1: 2,3-1: 2: 9$ and the time of the process 119-137 minutes.
\end{abstract}

Keywords: abies ethanol lignin, sulfation, sulfamic acid, urea, 1,4-dioxane, sulfated ethanol lignin, process optimization.

Citation: Kazachenko A.S., Vasilyeva N.Yu., Sudakova I.G., Levdansky V.A., Lutoshkin M.A., Kuznetsov B.N. Numerical optimization of the abies ethanol lignin sulfation process with sulfamic acid in 1,4-dioxane medium in the presence of urea, J. Sib. Fed. Univ. Chem., 2020, 13(2), 232-246. DOI: 10.17516/1998-2836-0178

(C) Siberian Federal University. All rights reserved

This work is licensed under a Creative Commons Attribution-NonCommercial 4.0 International License (CC BY-NC 4.0).

* Corresponding author E-mail address: inm@icct.ru 


\title{
Численная оптимизация процесса \\ сульфатирования этаноллигнина древесины пихты \\ сульфаминовой кислотой
}

в среде 1,4-диоксана в присутствии мочевины

\author{
А.С. Казаченко ${ }^{\text {, }}$ Н.Ю. Васильева ${ }^{\text {a, }}$, И.Г. Судакова ${ }^{a}$, \\ В.А. Левданский ${ }^{\text {a }}$ М.А. Лутошкин ${ }^{\text {a }}$, Б.Н. Кузнецов ${ }^{\text {a, }}$ \\ ${ }^{a}$ Институт химии и химической технологии СО РАН \\ ФИЦ «Красноярский научный цуентр СО РАН» \\ Российская Федерачия, Красноярск \\ ${ }^{\sigma}$ Сибирский федеральный университет \\ Российская Федераџия, Красноярск
}

Аннотация. Расчетными методами найдены оптимальные условия процесса сульфатирования этаноллигнина пихты сульфаминовой кислотой в среде 1,4-диоксана в присутствии мочевины. Установлено влияние таких факторов, как отношения лигнин/сульфатирующий комплекс (Л/СК), температура и продолжительность процесса сульфатирования на содержание серы в сульфатированном этаноллигнине пихты и его выход. Дисперсионный анализ полученных математических моделей свидетельствует о их хороших прогностических свойствах. Установлены оптимальные условия сульфатирования этаноллигнина пихты, обеспечивающие получение водорастворимого сульфатированного лигнина с высоким выходом (до $100 \%$ и содержанием серы (до 7,9 \% мас.): температура 95-100 ${ }^{\circ} \mathrm{C}$, соотношение Л/СК 1:2,3-1:2:9 и продолжительность процесса 119-137 мин.

Ключевые слова: этаноллигнин пихты, сульфатирование, сульфаминовая кислота, мочевина, 1,4-диоксан, сульфатированный этаноллигнин, оптимизация процесса.

Цитирование: Казаченко, А.С. Численная оптимизация процесса сульфатирования этаноллигнина древесины пихты сульфаминовой кислотой в среде 1,4-диоксана в присутствии мочевины / А.С. Казаченко, Н.Ю. Васильева, И.Г. Судакова, В.А. Левданский, М.А. Лутошкин, Б.Н. Кузнецов // Журн. Сиб. федер. ун-та. Химия, 2020. 13(2). С. 232246. DOI: $10.17516 / 1998-2836-0178$

\section{Введение}

Растительная биомасса - возобновляемый и практически неисчерпаемый ресурс для получения многих химических веществ, биотоплив и энергии [1]. Целлюлоза, гемицеллюлозы и лигнин являются тремя основными компонентами растительной биомассы [2]. Лигнин, содержащийся в древесной биомассе в количестве 15-35 \% мас., - это ароматический полимер, который состоит из фенилпропановых единиц, содержащих в качестве заместителей различные органические группы, в том числе эфирные, карбоксильные и спиртовые [3].

Традиционные процессы химической переработки древесины направлены в основном на получение целлюлозы как целевого продукта, при этом лигнин остается в качестве крупно-

$$
-233-
$$


тоннажного отхода [4], методы эффективной утилизации которого пока отсутствуют. Однако разрабатываемые в последние годы новые способы получения целлюлозы, основанные на процессах органосольвентной варки древесины в присутствии различных органических растворителей $[5,6]$, более экологически безопасны по сравнению с сульфитными и сульфатными технологиями. Кроме того, получаемые органосольвентные лигнины не содержат серы, обладают относительно небольшой молекулярной массой [7-9], более химически активны, чем технические лигнины, хорошо растворяются в органических растворителях, что облегчает их дальнейшую химическую переработку.

Модификация лигнина сульфатными группами придает ему способность растворяться в воде и увеличивает его биоразлагаемость $[10,11]$. Кроме того, известно, что сульфатированный лигнин обладает антикоагулянтной и противовирусной активностью, благодаря чему может найти применение в фармацевтике и медицине [12-15].

Для получения сульфатированных производных органических соединений широкое распространение получили комплексы серного ангидрида с различными основаниями (триэтиламин, пиридин и др.) $[16,17]$. В отличие от традиционных сульфатирующих агентов сульфаминовая кислота является малотоксичным и коррозионно не агрессивным соединением.

Ранее авторами был предложен способ сульфатирования этаноллигнина древесины пихты сульфаминовой кислотой в среде 1,4-диоксана в присутствии мочевины [18]. В работах [19, 20] изучено влияние продолжительности сульфатирования этаноллигнина пихты смесью сульфаминовая кислота-мочевина в среде 1,4-диоксана на содержание серы в сульфатах этаноллигнина и выход сульфатированного этаноллигнина.

В настоящей работе проведена численная оптимизация процесса сульфатирования этаноллигнина древесины пихты сульфаминовой кислотой в среде 1,4-диоксана в присутствии мочевины с целью определения оптимальных условий процесса, обеспечивающих максимальный выход сульфатированного этаноллигнина пихты с высоким содержанием серы.

\section{Экспериментальная часть}

В работе использовали этаноллигнин, выделенный из древесины пихты сибирской (Ábies sibírica), содержащей (\% в расчете на массу абсолютно сухой древесины): 45,7 - целлюлозы; 25,3 - лигнина; 17,7 - гемицеллюлоз; 6,2 - экстрактивных веществ; 0,5 - золы. Обессмоленные (в соответствии со стандартным методом ANSI/ASTM D 1105) воздушно-сухие (влажность-менее $1 \%$ мас.) опилки древесины измельчали на вибростенде ВР-2. Этаноллигнин из древесины извлекали экстракцией смесью этанол-вода при температуре $185^{\circ} \mathrm{C}$ и последующим осаждением холодной водой по методике [21]. Выход этаноллигнина составил 9,5 \% мас. от массы древесины.

Сульфатирование этаноллигнина смесью сульфаминовой кислоты и мочевины осуществляли по методике [20].

Элементный анализ сульфатированного лигнина проводили на элементном анализаторе FlashEA-1112 (ThermoQuestItalia).

Выход сульфатированного этаноллигнина пихта $X$ (\% от количества исходного этаноллигнина) рассчитывали по формуле 


$$
X(\%)=\frac{m_{S L}}{m_{E L}} \times 100 \%
$$

где $\mathrm{m}_{\mathrm{SL}}$ - масса воздушно-сухого сульфатированного этаноллигнина, г; $\mathrm{m}_{\mathrm{EL}}$ - масса навески воздушно-сухого этаноллигнина, г.

Численная оптимизация процесса сульфатирования этаноллигнина пихты сульфаминовой кислотой проводилась с применением программного обеспечения Statgraphics Centurion XVI, блок DOE (Design of Experiment), по методике, описанной в работе [22].

В исследование включены в качестве независимых переменных три фактора (в скобках уровни их варьирования): $\mathrm{X}_{1}$ - соотношение Л/СК (1:1,2. 1:1,5, 1:2,0, 1:3,0 г/моль); $\mathrm{X}_{2}$ - температура $\left(80,90,100{ }^{\circ} \mathrm{C}\right) ; \mathrm{X}_{3}$ - продолжительность процесса сульфатирования этаноллигнина пихты $(60,120,180$ мин). Результат процесса сульфатирования характеризовали двумя выходными параметрами: $\mathrm{Y}_{1}$ - содержание серы в сульфатированном этаноллигнине, \% мас.; $\mathrm{Y}_{2}$ - выход сульфатированного этаноллигнина пихты, \% мас.

Экспериментальные данные, интервалы варьирования факторов и выходные параметры приведены в табл. 1.

\section{Результаты и обсуждение}

При выборе оптимальных условий процесса сульфатирования этаноллигнина древесины пихты сульфаминовой кислотой в 1,4-диоксане задачей оптимизации было определение значений параметров процесса, обеспечивающих достижение максимального содержания серы в сульфатированном этаноллигнине пихты с максимальным выходом продукта сульфатирования.

\section{1. Влияние условий процесса сульфатирования на содержание серы}

в сульфатированном этаноллигнине пихты

Зависимость содержания серы в сульфатированном этаноллигнине пихты от переменных факторов - соотношения Л:СК и температуры процесса сульфатирования этаноллигнина пихты сульфаминовой кислотой в 1,4-диоксане в присутствии основного катализатора - мочевины при продолжительности процесса 120 мин аппроксимированы уравнением регрессии:

$$
Y_{1}=-6,55556+3,11667 X_{1}+0,1767 X_{2}
$$

Дисперсионный анализ показал, что в границах принятых условий эксперимента существенный вклад в суммарную дисперсию вносит фактор соотношения Л:СК - $\mathrm{X}_{1}$ (табл. 2). На это указывают высокие значения дисперсионных отношений $\mathrm{F}$, называемые также эффективностями влияния.

Влияние источника дисперсии на выходной параметр считается статистически значимым, если уровень значимости $\mathrm{P}<0,05$, соответствующий доверительной вероятности $95 \%$. Согласно вышеописанной модели оптимальными условиями сульфатирования лигнина при продолжительности процесса 120 мин являются соотношение Л/СК 1:2,9 и температура процесса $96{ }^{\circ} \mathrm{C}$.

На рис. 1 приведены результаты сравнения значений выходного параметра $\mathrm{Y}_{1}$, полученных в эксперименте, со значениями, прогнозируемыми по уравнению (1). Прямая линия соот- 
Таблица 1. Условия и результаты эксперимента

Table 1. Experimental conditions and results

\begin{tabular}{|c|c|c|c|c|c|}
\hline № & $\begin{array}{c}\text { Соотношение } \\
\text { Л:СК }\left(\mathrm{X}_{1}\right) \\
\end{array}$ & $\begin{array}{c}\text { Температура, }{ }^{\circ} \mathrm{C} \\
\left(\mathrm{X}_{2}\right)\end{array}$ & $\begin{array}{c}\text { Продолжительность, } \\
\text { мин }\left(\mathrm{X}_{3}\right) \\
\end{array}$ & $\begin{array}{c}\text { Содержание } \\
\text { серы, \% мас. }\left(\mathrm{Y}_{1}\right)\end{array}$ & $\begin{array}{c}\text { Выход, \% мас. } \\
\left(\mathrm{Y}_{2}\right)\end{array}$ \\
\hline 1 & $1: 1,2$ & 80 & 60 & 4,6 & 39,4 \\
\hline 2 & $1: 1,2$ & 80 & 120 & 5,3 & 48,9 \\
\hline 3 & $1: 1,2$ & 80 & 180 & 5,6 & 56,2 \\
\hline 4 & $1: 1,2$ & 90 & 60 & 5,2 & 54,3 \\
\hline 5 & $1: 1,2$ & 90 & 120 & 6,0 & 79,7 \\
\hline 6 & $1: 1,2$ & 90 & 180 & 6,3 & 85,3 \\
\hline 7 & $1: 1,2$ & 100 & 60 & 5,3 & 61,7 \\
\hline 8 & $1: 1,2$ & 100 & 120 & 6,1 & 88,9 \\
\hline 9 & $1: 1,2$ & 100 & 180 & 6,5 & 96,3 \\
\hline 10 & $1: 1,5$ & 80 & 60 & 5,1 & 53,4 \\
\hline 11 & $1: 1,5$ & 80 & 120 & 5,8 & 63,1 \\
\hline 12 & $1: 1,5$ & 80 & 180 & 6,7 & 68,1 \\
\hline 13 & $1: 1,5$ & 90 & 60 & 5,7 & 73,8 \\
\hline 14 & $1: 1,5$ & 90 & 120 & 6,3 & 88,3 \\
\hline 15 & $1: 1,5$ & 90 & 180 & 7,3 & 98,6 \\
\hline 16 & $1: 1,5$ & 100 & 60 & 6,0 & 76,8 \\
\hline 17 & $1: 1,5$ & 100 & 120 & 6,8 & 96,6 \\
\hline 18 & $1: 1,5$ & 100 & 180 & 7,6 & 104,1 \\
\hline 19 & $1: 2,0$ & 80 & 60 & 5,7 & 72,8 \\
\hline 20 & $1: 2,0$ & 80 & 120 & 6,6 & 90,4 \\
\hline 21 & $1: 2,0$ & 80 & 180 & 7,4 & 93,1 \\
\hline 22 & $1: 2,0$ & 90 & 60 & 6,0 & 85,7 \\
\hline 23 & $1: 2,0$ & 90 & 120 & 7,0 & 100,1 \\
\hline 24 & $1: 2,0$ & 90 & 180 & 7,7 & 103,1 \\
\hline 25 & $1: 2,0$ & 100 & 60 & 6,5 & 97,4 \\
\hline 26 & $1: 2,0$ & 100 & 120 & 7,6 & 103,0 \\
\hline 27 & $1: 2,0$ & 100 & 180 & 7,9 & 103,9 \\
\hline 28 & $1: 3,0$ & 80 & 60 & 7,0 & 88,6 \\
\hline 29 & $1: 3,0$ & 80 & 120 & 7,5 & 99,6 \\
\hline 30 & $1: 3,0$ & 80 & 180 & 7,9 & 102,4 \\
\hline 31 & $1: 3,0$ & 90 & 60 & 7,3 & 95,4 \\
\hline 32 & $1: 3,0$ & 90 & 120 & 7,7 & 102,8 \\
\hline 33 & $1: 3,0$ & 90 & 180 & 7,9 & 103,3 \\
\hline 34 & $1: 3,0$ & 100 & 60 & 7,7 & 101,8 \\
\hline 35 & $1: 3,0$ & 100 & 120 & 7,9 & 106,5 \\
\hline 36 & $1: 3,0$ & 100 & 180 & 7,9 & 107,2 \\
\hline
\end{tabular}


Таблица 2. Дисперсионный анализ для $\mathrm{Y}_{1}$ в зависимости от $\mathrm{X}_{1}$ и $\mathrm{X}_{2}$

Table 2. Analysis of variance for $\mathrm{Y}_{1}$ depending on $\mathrm{X}_{1}$ and $\mathrm{X}_{2}$

\begin{tabular}{|c|c|c|c|c|}
\hline $\begin{array}{c}\text { Источник } \\
\text { дисперсии }\end{array}$ & Сумма квадратов & $\begin{array}{c}\text { Число степеней } \\
\text { свободы }\end{array}$ & Эффективность F & $\begin{array}{c}\text { Уровень } \\
\text { значимости Р }\end{array}$ \\
\hline $\mathrm{X}_{1}$ & 5,415 & 1 & 146,21 & 0,0012 \\
\hline $\mathrm{X}_{2}$ & 0,80667 & 1 & 21,78 & 0,0186 \\
\hline
\end{tabular}

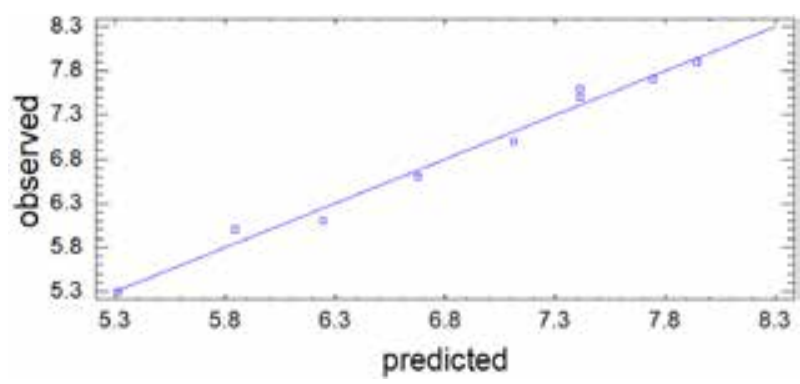

Рис. 1. Сравнение экспериментальных и расчетных значений содержания серы в сульфатированном этаноллигнине пихты в процессе сульфатирования при варьировании соотношения Л/СК и температуры

Fig. 1. Comparison of experimental and calculated values of sulfur content in sulfated abies ethanol lignin in sulfation process with varying the ratio $\mathrm{L} / \mathrm{SC}$ and process temperature

ветствует расчетным (прогнозируемым) значениям $\mathrm{Y}_{1}$, точки - экспериментальные значения. Близость большинства «экспериментальных точек» к прямой указывает на хорошие прогностические свойства уравнения регрессии.

Графическое представление влияния переменных факторов процесса - соотношения Л/СК $\left(\mathrm{X}_{1}\right)$, температуры процесса $\left(\mathrm{X}_{2}\right)$ - на содержание серы в сульфатированном этаноллигнине в виде поверхностей отклика изображено на рис. 2.

Влияние соотношения Л:СК $\left(\mathrm{X}_{1}\right)$ и продолжительности процесса сульфатирования этаноллигнина пихты $\left(\mathrm{X}_{3}\right)$ на содержание серы $\left(\mathrm{Y}_{1}\right)$ в сульфатированном этаноллигнине описывается уравнением регрессии:

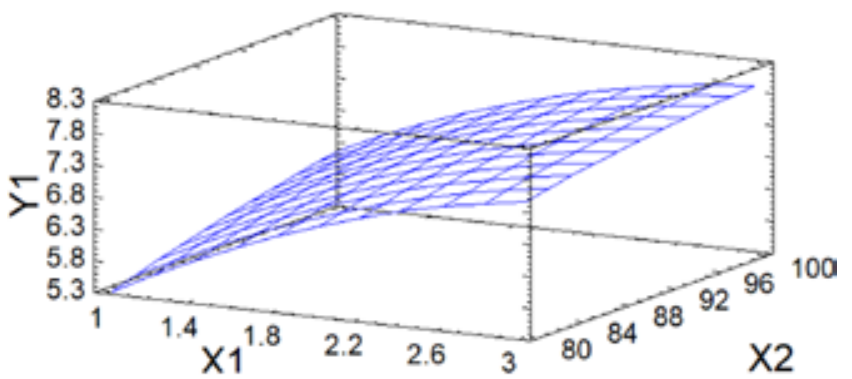

Рис. 2. Поверхность отклика выходного параметра содержание серы мас. \% $\mathrm{Y}_{1}$ от переменных факторов соотношения Л/СК $\mathrm{X}_{1}$ и температуры процесса $\mathrm{X}_{2}$ при продолжительности 120 мин

Fig. 2. Surface response of the output parameter $Y_{1}$ (sulfur content, wt. \%) as depending on variable factors $-X_{1}$ (L/SC ratio) and $\mathrm{X}_{2}$ (the process temperature) at time of process is $120 \mathrm{~min}$. 


$$
\mathrm{Y}_{1}=1,02222+3,1667 \mathrm{X}_{1}+0,03167 \mathrm{X}_{3}-0,433 \mathrm{X}_{1}^{2} .
$$

Данные дисперсионного анализа (табл. 3) свидетельствуют о хороших прогностических свойствах моделей: высокая эффективность всех компонентов уравнения регрессии, высокий коэффициент детерминации (97,4%), низкие уровни значимости (Р-критерий).

Оптимальными условиями для данной модели сульфатирования лигнина при температуре процесса $100{ }^{\circ} \mathrm{C}$ являются соотношение Л/СК 1:2,93 и продолжительность процесса 126 мин.

Хорошее соответствие вычисленных по уравнению (2) и измеренных значений выходных параметров, представленное на рис. 3 , говорит об адекватности уравнения регрессии результатам наблюдений и позволяет использовать его в качестве математической модели изучаемого процесса.

Таблица 3. Дисперсионный анализ для $\mathrm{Y}_{1}$ в зависимости от $\mathrm{X}_{1}$ и $\mathrm{X}_{3}$

Table 3. Analysis of variance for $\mathrm{Y}_{1}$ depending on $\mathrm{X}_{1}$ and $\mathrm{X}_{3}$

\begin{tabular}{|c|c|c|c|c|}
\hline $\begin{array}{c}\text { Источник } \\
\text { дисперсии }\end{array}$ & Сумма квадратов & $\begin{array}{c}\text { Число степеней } \\
\text { свободы }\end{array}$ & Эффективность F & $\begin{array}{c}\text { Уровень } \\
\text { значимости } \mathrm{P}\end{array}$ \\
\hline $\mathrm{X}_{1}$ & 5,22667 & 1 & 80,64 & 0,0029 \\
\hline $\mathrm{X}_{3}$ & 1,30667 & 1 & 20,16 & 0,0206 \\
\hline $\mathrm{X}_{1}{ }^{2}$ & 0,37556 & 1 & 5,79 & 0,0953 \\
\hline
\end{tabular}

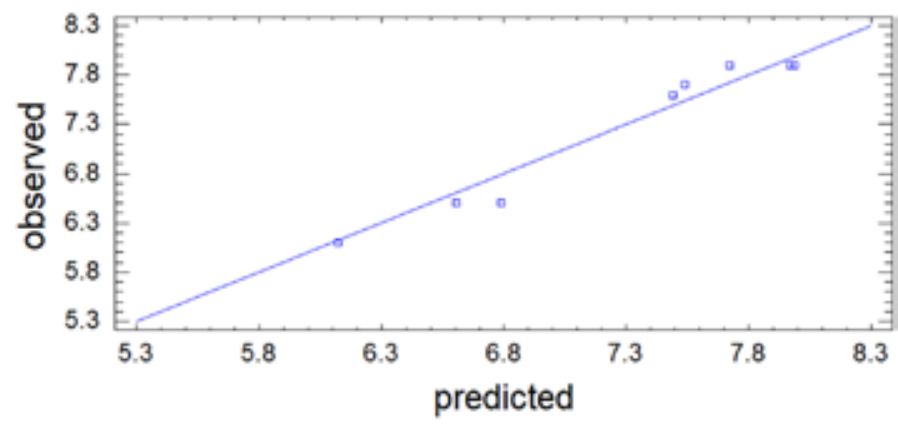

Рис. 3. Сравнение экспериментальных и расчетных значений содержания серы в сульфатированном этаноллигнине пихты в процессе сульфатирования при варьировании соотношения Л/СК и продолжительности

Fig. 3. Comparison of experimental and calculated values of sulfur content in sulfated abies ethanol lignin in sulfation process with varying the ratio $\mathrm{L} / \mathrm{SC}$ and time of the process

На рис. 4 представлено графическое отображение влияния переменных факторов - соотношения Л:СК $\left(\mathrm{X}_{1}\right)$ и продолжительности процесса $\left(\mathrm{X}_{3}\right)$ при температуре $100{ }^{\circ} \mathrm{C}$ в виде поверхности отклика.

Влияние продолжительности сульфатирования этаноллигнина пихты $\left(\mathrm{X}_{2}\right)$ и температуры процесса $\left(\mathrm{X}_{3}\right)$ при соотношении Л/СК 1:3 на значения выходного параметра $\mathrm{Y}_{1}$ (содержание серы, \% мас.) описывается нелинейным уравнением регрессии:

$$
-238-
$$




$$
\mathrm{Y}_{1}=3,3389+0,0233 \mathrm{X}_{2}+0,036528 \mathrm{X}_{3}+0,0002917 \mathrm{X}_{2} \mathrm{X}_{3}-0,0000232 \mathrm{X}_{3}^{2} .
$$

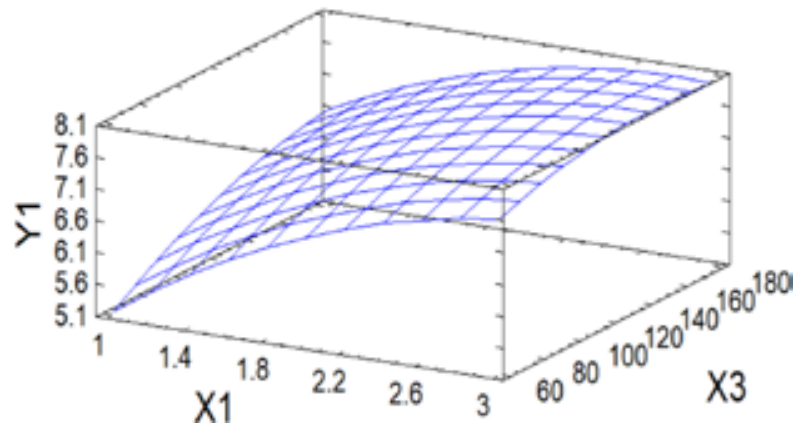

Рис. 4. Поверхность отклика выходного параметра (содержание серы мас. \%) $\mathrm{Y}_{1}$ от переменных факторовсоотношения (Л:СК) $\mathrm{X}_{1}$ и продолжительности процесса $\mathrm{X}_{3}$ при температуре $100{ }^{\circ} \mathrm{C}$

Fig. 4. Surface response of the output parameter $\mathrm{Y}_{1}$ (sulfur content, wt. \%) as depending on variable factors $-\mathrm{X}_{1}$ (L:SC ratio) and $\mathrm{X}_{3}$ (time of the process) at a temperature of $100{ }^{\circ} \mathrm{C}$

Согласно данным дисперсионного анализа (табл. 4), показаны хорошие прогностические свойства модели: высокая эффективность всех компонентов уравнения регрессии, высокий коэффициент детерминации (99,2 \%), низкие уровни значимости (Р- критерий). Оптимальными условиями для данной модели сульфатирования лигнина при соотношении Л/СК 1:3 являются температура $98^{\circ} \mathrm{C}$ и продолжительность процесса 137 мин.

Таблица 4. Дисперсионный анализ для $\mathrm{Y}_{1}$ в зависимости от $\mathrm{X}_{2}$ и $\mathrm{X}_{3}$

Table 4. Analysis of variance for $\mathrm{Y}_{1}$ depending on $\mathrm{X}_{2}$ and $\mathrm{X}_{3}$

\begin{tabular}{|c|c|c|c|c|}
\hline $\begin{array}{c}\text { Источник } \\
\text { дисперсии }\end{array}$ & Сумма квадратов & $\begin{array}{c}\text { Число степеней } \\
\text { свободы }\end{array}$ & Эффективность $\mathrm{F}$ & $\begin{array}{c}\text { Уровень } \\
\text { значимости Р }\end{array}$ \\
\hline $\mathrm{X}_{2}$ & 0,201667 & 1 & 311,14 & 0,0004 \\
\hline $\mathrm{X}_{3}$ & 0,481667 & 1 & 743,14 & 0,0001 \\
\hline $\mathrm{X}_{2} \mathrm{X}_{3}$ & 0,122500 & 1 & 189,00 & 0,0008 \\
\hline $\mathrm{X}_{3}{ }^{2}$ & 0,013889 & 1 & 21,43 & 0,0190 \\
\hline
\end{tabular}

Хорошее соответствие вычисленных по уравнению (3) и экспериментальных значений выходных параметров, представленное на рис. 5, говорит об адекватности уравнения регрессии результатам наблюдений и позволяет использовать его в качестве математической модели изучаемого процесса.

На рис. 6 представлено графическое отображение влияния переменных факторов продолжительности процесса сульфатирования этаноллигнина пихты $\left(\mathrm{X}_{2}\right)$ и температуры процесса $\left(\mathrm{X}_{3}\right)$ на выходной параметр - содержание серы в сульфатированном этаноллигнине $\left(\mathrm{Y}_{1}\right)$ в виде поверхности отклика при соотношении Л/СК 1:3, полученной с использованием уравнения (3). 


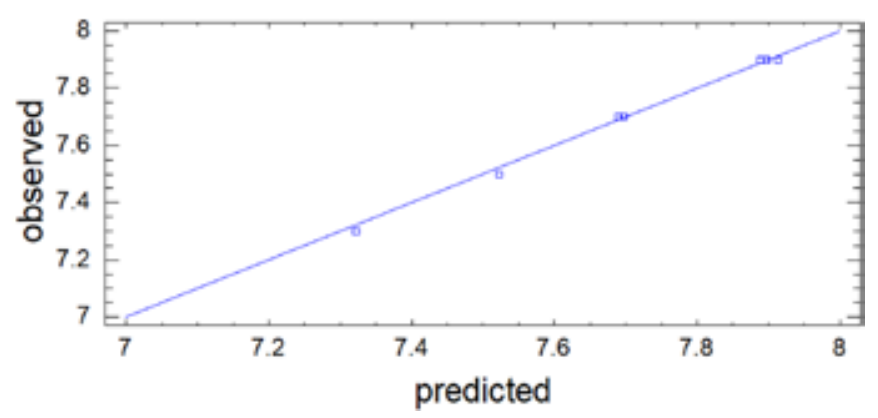

Рис. 5. Сравнение экспериментальных и расчетных значений содержания серы (мас. \%) в образце этаноллигнина пихты в процессе сульфатирования при варьировании температуры и продолжительности

Fig. 5. Comparison of experimental and calculated values of sulfur content (wt. \%) in a sample of abies ethanol lignin in the sulfation process with varying temperature and time of the process

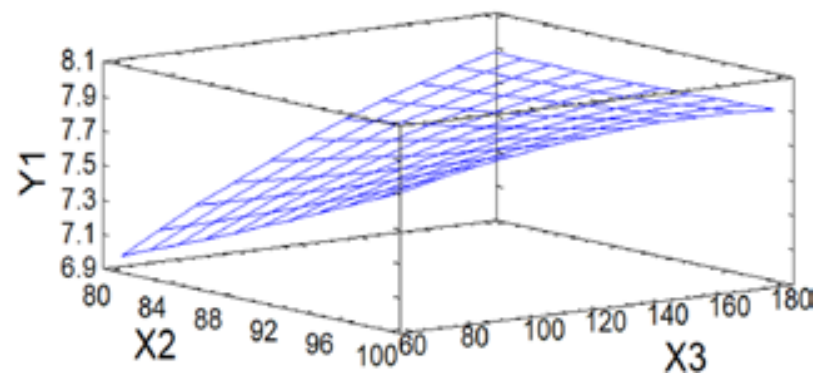

Рис. 6. Поверхность отклика выходного параметра содержание серы (мас. \%) $\mathrm{Y}_{1}$ от переменных факторов температуры $\left(\mathrm{X}_{2}\right)$ и продолжительности процесса сульфатирования этаноллигнина пихты $\left(\mathrm{X}_{3}\right)-$ при соотношении Л/СК $1: 3$

Fig. 6. Surface response of the output parameter sulfur content (wt. \%) $Y_{1}$ from variable factors - temperature $\left(\mathrm{X}_{2}\right)$ and the time of the sulfation process of abies ethanol lignin $\left(\mathrm{X}_{3}\right)$. with a ratio of $\mathrm{L} / \mathrm{SC} 1: 3$

\section{2. Влияние условий прочесса сульфатирования}

\section{на выход сульфатированного этаноллигнина пихты}

Методами математического моделирования установлены оптимальные условия процесса сульфатирования этаноллигнина древесины пихты, обеспечивающие максимальный выход сульфатированного этаноллигнина.

Зависимость выхода (мас. \%) сульфатированного этаноллигнина пихты от переменных факторов - соотношения Л:СК и температуры процесса сульфатирования этаноллигнина пихты сульфаминовой кислотой при продолжительности процесса 120 мин описываются уравнением регрессии:

$$
\mathrm{Y}_{2}=-569,539+133,81 \mathrm{X}_{1}+10,6367 \mathrm{X}_{2}-0,8675 \mathrm{X}_{1} \mathrm{X}_{2}
$$

Согласно данным, представленным в табл. 5, в границах принятых условий эксперимента существенный вклад в суммарную дисперсию вносит фактор соотношения Л:СК - $\mathrm{X}_{1}$. Значение коэффициента детерминации составляет 96,4 \%. Оптимальными условиями сульфатирования лигнина при продолжительности процесса 120 мин являются соотношение Л/СК 1:2,3 и температура процесса $91{ }^{\circ} \mathrm{C}$. Значении коэффициента детерминации 96,4%. 
Высокое значение коэффициента детерминации (96,4 \%) хорошо согласуется с данными рис. 7. Полученные экспериментальные значения практически находятся рядом с прямой, соответствующей расчетным данным.

Влияние переменных факторов - соотношения Л:СК $\left(\mathrm{X}_{1}\right)$ и температуры процесса $\left(\mathrm{X}_{2}\right)$ на выходной параметр - выход сульфатированного этаноллигнина $\left(\mathrm{Y}_{2}\right)$ - в виде поверхности отклика иллюстрируется рис. 8 .

Таблица 5. Дисперсионный анализ для $\mathrm{Y}_{2}$ в зависимости от $\mathrm{X}_{1}$ и $\mathrm{X}_{2}$

Table 5. Analysis of variance for $\mathrm{Y}_{2}$ depending on $\mathrm{X}_{1}$ and $\mathrm{X}_{2}$

\begin{tabular}{|c|c|c|c|c|}
\hline $\begin{array}{c}\text { Источник } \\
\text { дисперсии }\end{array}$ & Сумма квадратов & $\begin{array}{c}\text { Число степеней } \\
\text { свободы }\end{array}$ & Эффективность $\mathrm{F}$ & $\begin{array}{c}\text { Уровень } \\
\text { значимости } \mathrm{P}\end{array}$ \\
\hline $\mathrm{X}_{1}$ & 1290,67 & 1 & 42,92 & 0,0072 \\
\hline $\mathrm{X}_{2}$ & 543,402 & 1 & 18,07 & 0,0239 \\
\hline $\mathrm{X}_{1} \mathrm{X}_{2}$ & 301,022 & 1 & 10,01 & 0,0507 \\
\hline
\end{tabular}

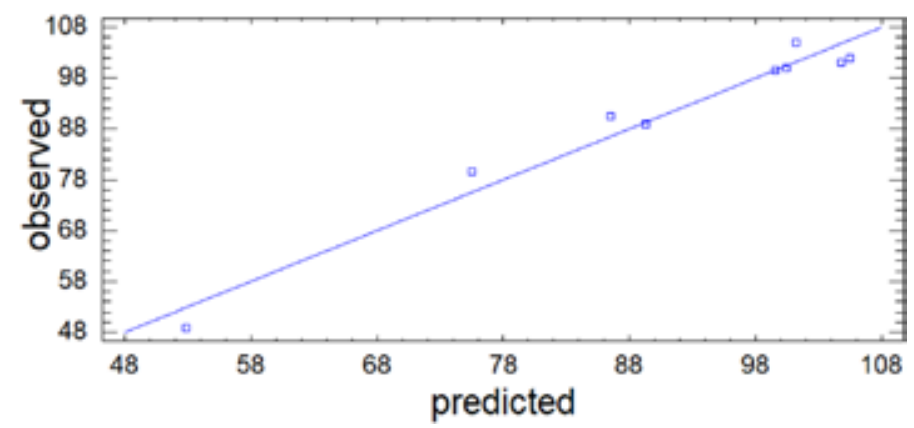

Рис. 7. Сравнение экспериментальных и расчетных значений выхода сульфатированного этаноллигнина пихты в процессе сульфатирования при варьировании соотношения Л/СК и температуры

Fig. 7. Comparison of the experimental and calculated values of the yield of sulfated abies ethanol lignin in the sulfation process with varying the ratio $\mathrm{L} / \mathrm{SC}$ and process temperature

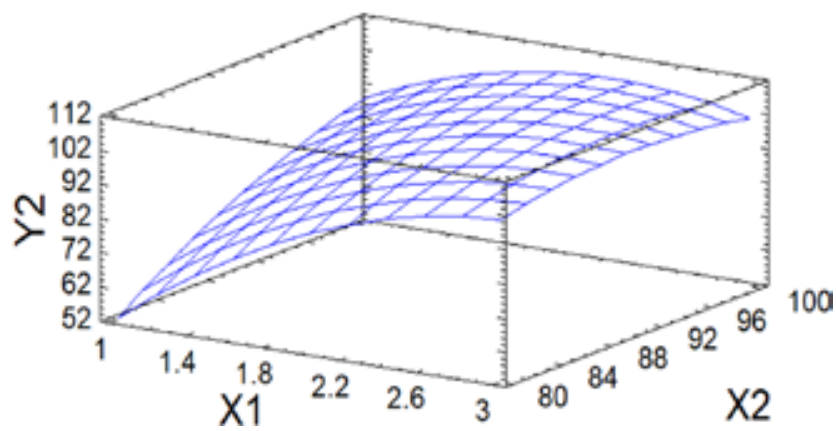

Рис. 8. Поверхность отклика выходного параметра выход сульфатированного этаноллигнина пихты $\mathrm{Y}_{2}$ от переменных факторов - соотношения Л:СК $\mathrm{X}_{1}$ и температуры процесса $\mathrm{X}_{2}$ при продолжительности 120 мин

Fig. 8. Surface response of the output parameter the yield of sulfated abies ethanol lignin $\mathrm{Y}_{2}$ from variable factors - the ratio A: SC $\mathrm{X}_{1}$ and process temperature $\mathrm{X}_{2}$ for time of process $120 \mathrm{~min}$ 
Таблица 6. Дисперсионный анализ для $\mathrm{Y}_{2}$ в зависимости от $\mathrm{X}_{1}$ и $\mathrm{X}_{3}$

Table 6. Analysis of variance for $\mathrm{Y}_{2}$ depending on $\mathrm{X}_{1}$ and $\mathrm{X}_{3}$

\begin{tabular}{|c|c|c|c|c|}
\hline $\begin{array}{c}\text { Источник } \\
\text { дисперсии }\end{array}$ & Сумма квадратов & $\begin{array}{c}\text { Число степеней } \\
\text { свободы }\end{array}$ & Эффективность F & $\begin{array}{c}\text { Уровень } \\
\text { значимости Р }\end{array}$ \\
\hline $\mathrm{X}_{1}$ & 852,042 & 1 & 130,62 & 0,0014 \\
\hline $\mathrm{X}_{3}$ & 721,607 & 1 & 110,63 & 0,0018 \\
\hline $\mathrm{X}_{1}{ }^{2}$ & 121,161 & 1 & 18,57 & 0,0230 \\
\hline $\mathrm{X}_{1} \mathrm{X}_{3}$ & 280,563 & 1 & 43,01 & 0,0072 \\
\hline $\mathrm{X}_{3}{ }^{2}$ & 42,9356 & 1 & 6,58 & 0,0828 \\
\hline
\end{tabular}

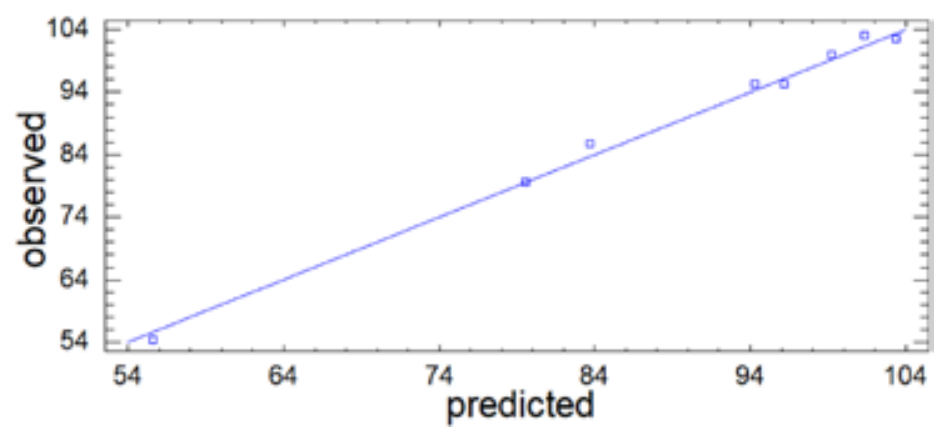

Рис. 9. Сравнение экспериментальных и расчетных значений выхода сульфатированного этаноллигнина в процессе сульфатирования при варьировании соотношения Л/СК и продолжительности

Fig. 9. Comparison of the experimental and calculated values of the yield of sulfated abies ethanol lignin by the sulfation process with varying the ratio $\mathrm{L} / \mathrm{SC}$ and the time of the process

Уравнение регрессии, описывающее влияние переменных факторов - соотношения Л:СК $\left(\mathrm{X}_{1}\right)$ и продолжительности процесса сульфатирования этаноллигнина пихты $\left(\mathrm{X}_{3}\right),-$ имеет вид

$$
\mathrm{Y}_{2}=-29,6778+59,8 \mathrm{X}_{1}+0,770833 \mathrm{X}_{3}-7,78333 \mathrm{X}_{1}^{2}-0,139583 \mathrm{X}_{1} \mathrm{X}_{3}-0,001287 \mathrm{X}_{3}{ }^{2}
$$

Дисперсионный анализ выявил (табл. 6), что в границах принятых условий эксперимента существенный вклад в суммарную дисперсию вносят оба фактора: соотношение Л:СК - $\mathrm{X}_{1}$ и температура процесса $-\mathrm{X}_{3}$. Как показано в табл. 6 , уровень значимости меньше, чем 0,05 , при значении коэффициента детерминации 98,9 \%. Оптимальными условиями для данной модели сульфатирования лигнина при температуре процесса $100{ }^{\circ} \mathrm{C}$ являются соотношение Л/СК 1:2,3 и продолжительность процесса 127 мин.

Наблюдается высокая сходимость экспериментальных данных со значениями, прогнозируемыми по уравнению (5) (рис. 9).

На рис. 10 представлено графическое отображение влияния переменных факторов $\mathrm{X}_{1}$ и $\mathrm{X}_{3}$ на выходной параметр $\mathrm{Y}_{2}$ в виде поверхности отклика, полученной с использованием уравнения (5).

Влияние переменных факторов - продолжительности $\left(\mathrm{X}_{2}\right)$ и температуры процесса сульфатирования этаноллигнина пихты $\left(\mathrm{X}_{3}\right)$ на выходной параметр $\mathrm{Y}_{2}$ (выход сульфатированного этаноллигнина, \% мас.) описывается уравнением регрессии: 


$$
\mathrm{Y}_{2}=68,2333-0,4933 \mathrm{X}_{2}+0,56028 \mathrm{X}_{3}-0,003083 \mathrm{X}_{2} \mathrm{X}_{3}-0,000861 \mathrm{X}_{3}^{2} .
$$

Данные дисперсионного анализа (табл. 7) указывают на высокие прогностические свойства моделей: высокая эффективность всех компонентов уравнения регрессии, высокий коэффициент детерминации (98,8 \%), низкие уровни значимости (Р-критерий). Оптимальными условиями для данной модели сульфатирования лигнина при соотношении Л/СК 1:3 являются температура $98^{\circ} \mathrm{C}$ и продолжительность процесса 119 мин.

Соответствие вычисленных по уравнению (6) и измеренных значений выходных параметров, представленное на рис. 11, свидетельствует об адекватности уравнения регрессии результатам наблюдений.

На рис. 12 представлено графическое отображение влияния переменных факторов - температуры $\left(\mathrm{X}_{2}\right)$ и продолжительности процесса сульфатирования этаноллигнина пихты $\left(\mathrm{X}_{3}\right)$ на выходной параметр - выход сульфатированного этаноллигнина, мас. \%, $\left(\mathrm{Y}_{2}\right)$ при соотношении Л/СК 1:3 в виде поверхности отклика.

В табл. 8 сопоставлены результаты вычисления параметров ( $\mathrm{Y}_{1}$ и $\left.\mathrm{Y}_{2}\right)$ по уравнениям (1-6) и их значения, наблюдавшиеся в эксперименте, а также относительные погрешности для приведенных моделей.

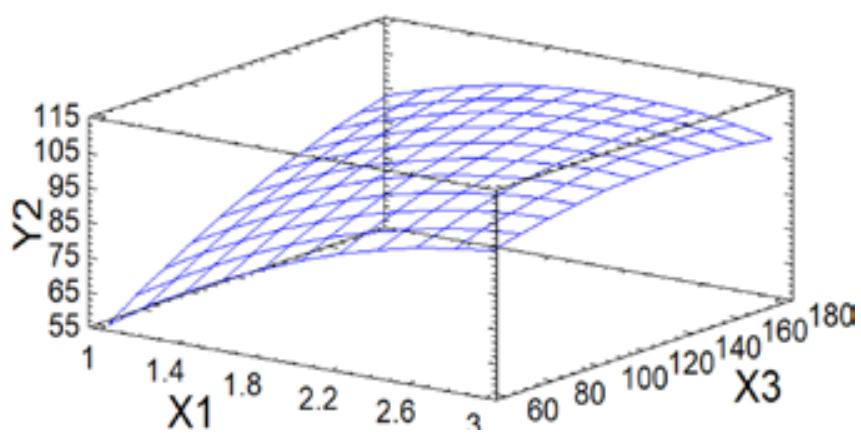

Рис. 10. Поверхность отклика выходного параметра выход сульфатированного этаноллигнина пихты (мас. \%) $\mathrm{Y}_{2}$ от переменных факторов - соотношения Л/СК $\mathrm{X}_{1}$ и продолжительности процесса $\mathrm{X}_{3}$ при температуре $100{ }^{\circ} \mathrm{C}$

Fig. 10. Surface response of the output parameter $\mathrm{Y}_{2}$ (yield of sulfated ethanol lignin, wt. \%) as depending on variable factors $-\mathrm{X}_{1}$ (ratio $\mathrm{L} / \mathrm{SC}$ ) and $\mathrm{X}_{2}$ (the process duration) at a stable temperature of $100{ }^{\circ} \mathrm{C}$

Таблица 7. Дисперсионный анализ для $\mathrm{Y}_{2}$ в зависимости от $\mathrm{X}_{2}$ и $\mathrm{X}_{3}$

Table 7. Analysis of variance for $\mathrm{Y}_{2}$ depending on $\mathrm{X}_{2}$ and $\mathrm{X}_{3}$

\begin{tabular}{|c|c|c|c|c|}
\hline $\begin{array}{c}\text { Источник } \\
\text { дисперсии }\end{array}$ & Сумма квадратов & $\begin{array}{c}\text { Число степеней } \\
\text { свободы }\end{array}$ & Эффективность $\mathrm{F}$ & $\begin{array}{c}\text { Уровень } \\
\text { значимости Р }\end{array}$ \\
\hline $\mathrm{X}_{2}$ & 94,4067 & 1 & 103,49 & 0,0020 \\
\hline $\mathrm{X}_{3}$ & 125,127 & 1 & 137,17 & 0,0013 \\
\hline $\mathrm{X}_{2} \mathrm{X}_{3}$ & 13,69 & 1 & 15,01 & 0,0304 \\
\hline $\mathrm{X}_{3}{ }^{2}$ & 19,22 & 1 & 21,07 & 0,0194 \\
\hline
\end{tabular}




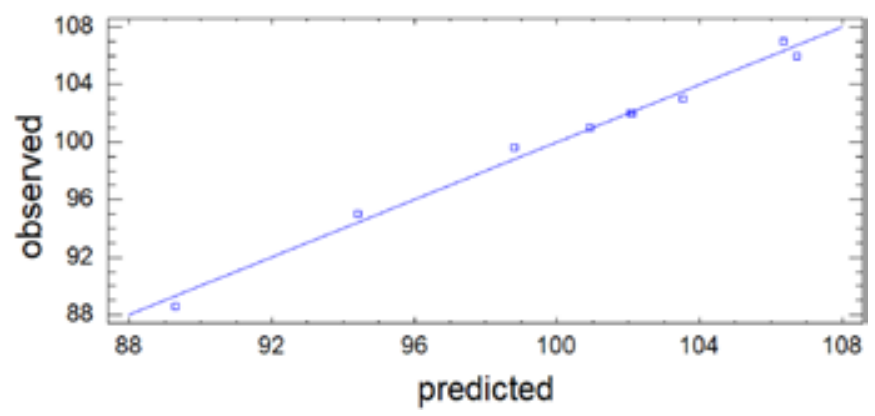

Рис. 11. Сравнение экспериментальных и расчетных значений выхода сульфатированного этаноллигнина (мас. \%) при варьировании температуры и продолжительности процесса сульфатирования

Fig. 11. Comparison of experimental and calculated values of the yield of sulfated ethanol lignin (wt. \%) with varying temperature and time of the sulfation process

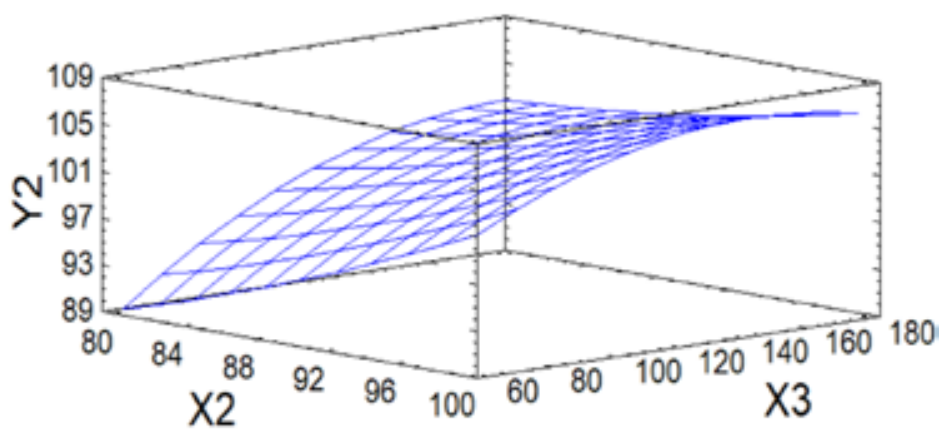

Рис. 12. Поверхность отклика выходного параметра выход сульфатированного этаноллигнина $\left(\mathrm{Y}_{2}\right)$ от переменных факторов - температуры $\left(\mathrm{X}_{2}\right)$ и продолжительности процесса сульфатирования этаноллигнина пихты $\left(\mathrm{X}_{3}\right)$ - при соотношении Л/СК 1:3

Fig. 12. Surface response of the yield parameter, the output of sulfated ethanol lignin $\left(\mathrm{Y}_{2}\right)$ from variable factors temperature $\left(\mathrm{X}_{2}\right)$ and the time of ethanol lignin sulfation $\left(\mathrm{X}_{3}\right)$ with ratio of L/SC 1:3

Таблица 8. Сравнение экспериментальных результатов и расчетных значений $\mathrm{Y}_{1}$ и $\mathrm{Y}_{2}$, вычисленных по уравнениям (1-6)

Table 8. Comparison of experimental results and calculated values of $\mathrm{Y}_{1}$ and $\mathrm{Y}_{2}$ calculated according to equations $(1-6)$

\begin{tabular}{|c|c|c|c|c|c|c|c|c|c|}
\hline \multirow{2}{*}{$\begin{array}{c}\text { № } \\
\text { уравн. }\end{array}$} & \multirow[t]{2}{*}{ № эксп. } & \multicolumn{2}{|c|}{$\begin{array}{c}\text { Содерж. серы, } \\
\text { \% мас. }\left(\mathrm{Y}_{1}\right)\end{array}$} & \multirow{2}{*}{$\begin{array}{c}\text { Отн. } \\
\text { погр. \% }\end{array}$} & \multirow{2}{*}{$\begin{array}{c}\text { № } \\
\text { уравн. }\end{array}$} & \multirow[t]{2}{*}{ № эксп. } & \multicolumn{2}{|c|}{$\begin{array}{c}\text { Выход, } \\
\% \text { мас. }\left(\mathrm{Y}_{2}\right)\end{array}$} & \multirow{2}{*}{$\begin{array}{c}\text { Отн. } \\
\text { погр. \% }\end{array}$} \\
\hline & & Эксп. & Расчет & & & & Эксп. & Расчет & \\
\hline 1 & 26 & 7,6 & 7,47 & 1,7 & 4 & 35 & 106,5 & 102,55 & 3,6 \\
\hline 2 & 17 & 6,8 & 6,95 & 1,4 & 5 & 27 & 103,9 & 105,10 & 1,1 \\
\hline 3 & 35 & 7,9 & 7,89 & 0,1 & 6 & 36 & 107,2 & 106,39 & 0,8 \\
\hline
\end{tabular}

Из представленных в табл. 8 данных следует, что полученные математические модели (1-6) хорошо описывают экспериментальные данные при значении относительной погрешности для фактора $\mathrm{Y}_{1}$ от 0,1 до 1,7 \% и для фактора $\mathrm{Y}_{2}$ от 0,8 до 3,6 \%. 


\section{Заключение}

Математическими методами установлены оптимальные условия процесса сульфатирования этаноллигнина древесины пихты сульфаминовой кислотой в присутствии мочевины, обеспечивающие получение водорастворимого сульфатированного производного лигнина с содержанием серы 7,5-7,9 \% мас. и выходом около 100 \% мас.

Данные дисперсионного анализа для полученных математических моделей свидетельствуют об их хороших прогностических свойствах: высокая эффективность всех компонентов уравнения регрессии, высокий коэффициент детерминации (96,4-99,2 \%), низкие уровни значимости и низкие значения относительной погрешности (0,1-3,8 \%). Полученные уравнения регрессии показывают, что оптимальными условиями для процесса сульфатирования этаноллигнина пихты смесью сульфаминовая кислота-мочевина в среде 1,4-диоксана являются температура 95-100 으, соотношение Л/СК 1:2,3-1:2:9 и продолжительность процесса 119-137 мин.

\section{Благодарности / Acknowledgements}

Исследование выполнено при поддержке Российского научного фонда (грант № 16-1310326). В работе использовано оборудование Красноярского регионального центра коллективного пользования ФИЦ КНЦ СО РАН.

The reported study was supported by Russian Science Foundation (Grant No. 16-13-10326). This work was conducted using the equipment of Krasnoyarsk Regional Research Equipment Centre of SBRAS.

\section{Список литературы / References}

1. Heitner C., Dimmel D., Schmidt J. Lignin and Lignans: Advances in Chemistry. CRC. Press: Taylor and Francis Group, 2010. 683 p.

2. Rowell R.M. Handbook of wood chemistry and wood composites. 2nd edn. CRC. Press: Taylor and Francis Group, 2012. 703 p.

3. Zouohua S., Balbit F., Alecsandra de Santi, Saravankumar E., Katalin B. Bright side of lignin depolymerization: Towards new platform chemicals. Chem. Rev. 2018. Vol. 118, P. 614-678.

4. Calvo-Flores F.G., Dobado J.A., Isac-García J., Martin-Martinez F. Lignin and lignans as renewable raw materials: chemistry, technology and applications. Chichester: Wiley, 2015. $482 \mathrm{p}$.

5. Alcaide L.J., Dominguez J.C.G., Ot I.P., Influence of cooking variables in the organosolv pulping of wheat straw using mixtures of ethanol, acetone, and water. TAPPI. 2003. Vol. 2(1), P. 27-31.

6. Popa V.I. Pulp Production and Processing: From Papermaking to High-Tech Products. Shropshire, UK: Smithers Rapra Technology, 2013. 542 p.

7. Kuznetsov B.N., Malyar Y.N., Kuznetsova S.A., Grishechko L.I., Kazachenko A.S., Levdansky A.V., Pestunov A.V, Boyandin A.N., Celzar A. Isolation, Study and Application of Organosolv Lignins (Review). J Sib. Fed. Univ. Chem. 2016. Vol. 4(9), P. 454-482.

8. Torre M.J., Moral A., Hernández M.D., Cabeza E., Tijero A. Organosolv lignin for biofuel. Ind. Crops Prod. 2013. Vol. 45, P. 58-63.

9. Arato C., Kendall Pye E., Gjennestad G. The Lignol Approach to Biorefining of Woody Biomass to Produce Ethanol and Chemicals in Applied Biochemistry and Biotechnology. Humana Press Inc. 2005. P. 121-124. 
10. Vinardell M.P., Mitjans M. Lignins and Their Derivatives with Beneficial Effects on Human Health. Int J Mol Sci. 2017. Vol. 18(6), P. 1219.

11. Prinsen P., Narani A., Hartog A.F., Wever R., Rothenberg G. Dissolving Lignin in Water through Enzymatic Sulfation with Aryl Sulfotransferase. Chem Sus Chem. 2017. Vol. 10(10), P. $2267-$ 2273.

12. Raghuraman A., Tiwari V., Zhao Q., Shukla D., Debnath A.K., Desai U.R. Viral inhibition studies on sulfated lignin, a chemically modified biopolymer and a potential mimic of heparan sulfate. Biomacromolecules 2007. Vol. 8, P. 1759-1763.

13. Henry B.L., Thakkar J.N., Liang A., Desai U.R. Sulfated, low molecular weight lignins inhibit a select group of heparin-binding serine proteases. Biochem Biophys Res Comm. 2012. Vol. 417(1), P. 382-386.

14. Henry B.L., Desai U.R. Sulfated low molecular weight lignins, allosteric inhibitors of coagulation proteinases via the heparin binding site, significantly alter the active site of thrombin and factor Xa compared to heparin. Thrombos Res. 2014. Vol. 134(5), P. 1123-1129.

15. Raghuraman A., Tiwari V., Zhao Q., Shukla D., Debnath A.K., Desai U.R. Viral Inhibition Studies on Sulfated Lignin, a Chemically Modified Biopolymer and a Potential Mimic of Heparan Sulfate. Biomacromolecules 2007. Vol. 8, P.1759-1763.

16. Al-Horani R.A., Desai U.R. Chemical sulfation of small molecules - advances and challenges. Tetrahedron. 2010. Vol. 66(16), P. 2907-2018.

17. Caputo H.E., Straub J.E., Grinstaff M.W. Design, synthesis, and biomedical applications of synthetic sulphated polysaccharides. Chem. Soc. Rev. 2019. Vol. 48, P. 2338-2365.

18. Патент 2641758 РФ. Васильева Н.Ю., Левданский В.А., Скворцова Г.П., Казаченко А.С., Кузнецов Б.Н. Способ сульфатирования органосольвентного лигнина. Опубл. 22.01.2018. [Patent 2641758 RU. Vasilyeva N.Yu., Levdansky V.A., Skvortsova G.P., Kazachenko A.S., Kuznetsov B.N. Method of sulfation of organosolv lignin. Publ. Date 22.01.2018 (In Russ.)].

19. Kuznetsov B.N., Vasilyeva N.Yu., Kazachenko A.S., Skvortsova G.P., Levdansky V.A., LutoshkinM.A. Development of the method of abies wood ethanollignin sulfonation using sulfamic acid. J Sib Fed Univ Chem. 2018. Vol. 1(11), P. 22-130.

20. Kuznetsov B.N., Vasilyeva N.Y., Kazachenko A.S. Levdansky V.A., Kondrasenko A.A., Malyar Yu.N., Skvortsova G.P., Lutoshkin M.A. Optimization of the process of abies ethanol lignin sulfation by sulfamic acid-urea mixture in 1,4-dioxane medium. Wood Sci Technol. 2020. https://doi. org/10.1007/s00226-020-01157-6

21. Quesada-Medina J., López-Cremades F.J., Olivares-Carrillo P. Organosolv extraction of lignin from hydrolyzed almond shells and application of the d-value theory. Bioresource Technology 2010. Vol. 101, P. 8252-8260.

22. Sudakova I.G., Garyntseva N.V., Yatsenkova O.V., Kuznetsov B.N. Optimization of aspen wood delignification by $\mathrm{H}_{2} \mathrm{O}_{2}$ with sulfuric acid catalyst. $J$ Sib Fed Univ Chem. 2013. Vol. 6, P. 76-84. 